\title{
Design and development of apparatus to provide repeatable surface temperature-time treatments on inoculated food samples
}

\author{
4 Alan M. Foster ${ }^{\text {a,* }}$, Laurence P. Ketteringham ${ }^{\text {a }}$, Mark J. Swain ${ }^{\text {a }}$, Alain Kondjoyan ${ }^{\text {b }}$, \\ Michel Havet ${ }^{\mathrm{c}}$, Olivier Rouaud ${ }^{\mathrm{c}}$, Judith A. Evans ${ }^{\mathrm{c}}$ \\ ${ }^{a}$ FRPERC, University of Bristol, Churchill Building, Langford, Bristol BS40 5DU, UK \\ ${ }^{\mathrm{b}}$ INRA, Station de Recherches sur la Viande, 63122 St. Genès Champanelle, France \\ ${ }^{\mathrm{c}}$ ENITIAA, rue de la Géraudière, BP 82225, 44322 Nantes Cedex 3, France
}

the sample's surface temperature in a pre-defined manner. The test apparatus was therefore designed to (1) heat the sample from a set starting temperature, at a set rate, until a set end of heating temperature was reached, (2) hold the sample at the end of heating temperature for a defined period then (3) cool the sample in a controlled manner to a temperature at which no microbial growth can occur. At least 10 sampling points were required within each heating-holding-cooling regime to allow sufficient data for the microbial modelling work, and so the apparatus was designed such that samples could be removed at predefined points in the cycle. Samples that were removed for analysis during the treatment needed to be cooled immediately to prevent any further microbial activity.

The original specification of the apparatus was that it should be able to produce repeatable temperature cycles, with an average error of less than $\pm 2{ }^{\circ} \mathrm{C}$, on food 
50 surfaces over any temperature profile, encompassed by 51 the 'slow' and 'rapid' cycles. The extremes of these cycles 52 are represented by, for the slow treatment, a surface 53 temperature rise from 5 to $60^{\circ} \mathrm{C}$ in $600 \mathrm{~s}$, dwell time 54 at $60^{\circ} \mathrm{C}$ of $600 \mathrm{~s}$ followed by cooling to $5^{\circ} \mathrm{C}$ in $600 \mathrm{~s}$, and for the rapid treatment, surface temperature rise from 5 to $120^{\circ} \mathrm{C}$ in $5 \mathrm{~s}$, a $0 \mathrm{~s}$ dwell time at $120^{\circ} \mathrm{C}$ followed by cooling to $5^{\circ} \mathrm{C}$ in $5 \mathrm{~s}$. The apparatus should also be able to produce wet (condensing steam) and dry (evaporating) environments.

There was also the requirement to develop methods for accurately measuring food surface and process temperatures. The specification stated that temperatures should be measured to an accuracy of better than $\pm 1{ }^{\circ} \mathrm{C}$ during the slow heating, holding and cooling processes. The temperatures in the 'rapid' heating and cooling process should be measured with an accuracy better than $\pm 2{ }^{\circ} \mathrm{C}$ throughout the process.

Prototype apparatus was manufactured and tested at the Food Refrigeration and Process Engineering Research Centre, University of Bristol (FRPERC). Four more of the systems were manufactured and delivered to the project partners. The apparatus needed to be simple to operate, safe and reliable, since microbiologists, food technologists and engineers from three different EU countries would use it. It was designed so that researchers and technicians in the institutions would be able operate the equipment with little training.

The following sections explain in detail the development of each part of the system.

\section{Development of system}

After initial discussions with the project partners, a number of changes were made to the initial specifications. The maximum temperature of the rapid cycle was set at $100^{\circ} \mathrm{C}$ since it was not expected that bacteria would survive above this temperature. The minimum time for the rapid heating cycle was lengthened to allow single-phase heaters to be used. The minimum time for the cooling was increased since rapid cooling to temperatures where further microbial activity would be inhibited was more easily carried out by placing the sample into a stomacher bag immediately after it came out of the system (McGovern, McCann, \& Sheridan, 2005) containing cold diluent.

At an early stage of development, studies were carried out to ensure that the high air velocities achieved over the surface of the sample would not detach an excessive number of microorganisms from the sample surface. Loss of microorganisms could reduce the final counts (and so cause a non-thermal reduction in the bacterial numbers) and lead to safety problems, as many of the bacteria used were pathogenic or genetically modified. The outlet air was also filtered to ensure that no bacteria left the treatment chamber in the air stream. This filter is described in detail in Section 4.4.

The studies showed that a very small number of bacteria were removed from the sample, but that the filter prevented them from leaving the process chamber.

The apparatus was designed to repeatably produce controlled surface temperature-time treatments on samples during rapid heating and cooling cycles and accurate measurement of surface temperatures during the process. Samples had to be easy to produce and inoculate and have a known surface area exposed to the heating and cooling environment. The heating and cooling system had to produce rapid but uniform treatment of the whole sample surface. The main options considered were: (1) whether to have separate dry, wet and cooling chambers or carry out the whole cycle in one chamber; (2) use a contact or non-contact method of measuring and hence controlling the surface temperature of the food sample; and (3) deliver the heating and cooling environment across the surface of the sample or directly impinge it onto the surface. These different options were investigated using a combination of direct experimentation, mathematical heat transfer modelling and computational fluid dynamics (CFD).

The design that was chosen from these options was to automatically introduce the inoculated sample into a single chamber and carry out all of the process cycles in that chamber. Having multiple chambers would have increased the size of the apparatus and its complexity. It would have required surface temperature measurement in each chamber, movement of the sample between chambers and filtration of each chamber.

A non-contact method of measuring surface temperature (IR thermometer) that would not interact with the microorganisms on the surface was chosen because it was felt that any contact may affect the bacterial numbers on the surface and measuring true, rapidly changing surface temperatures by any other method was extremely difficult (Hoke, Housska, Kyyhos, Landfeld, \& Pipekb, 2003; James, Goksoy, Corry, \& James, 2000).

It was not practical to introduce all of the treatment streams (heating, cooling and steam) directly from above and measure the surface temperature using an IR thermometer due to lack of space. This was especially the case with one of the systems since the project partner using it needed to view the product surface from above with a light sensitive camera. The treatment streams were, therefore, delivered across (parallel to) the surface of the sample.

A control system with a graphical user interface (GUI) was employed to ensure that the apparatus was safe, repeatable and easy to use.

A borosilicate glass Petri dish (part no. 402/0060/01, Merck Ltd., Dorset, UK) with an external diameter of $55 \mathrm{~mm}$ and height of $19 \mathrm{~mm}$ was chosen as the sample holder. Food samples could be readily inserted into 
159 the dish with a known surface area exposed at the top.

160 The size provided a good compromise between a small 161 sample, whose surface temperature would be easier to 162 change and a large sample that would allow easier inoc163 ulation and recovery of microorganisms for analysis.

164 The sample dish was held (friction fit) on an alumin165 ium support connected to a motor that rotated the sam166 ple at a frequency of $0.8 \mathrm{~Hz}$. The purpose of the rotation 167 was to create a more even heating and cooling at the sur168 face. Without rotation the leading edge of the sample 169 would be subjected to higher heating and cooling rates. 170 To keep the heating as one dimensional as possible 171 (from the top surface only), a nickel ring was placed 172 around the sample, with the cavity inside the ring pro173 viding the insulation. A schematic of the complete sam174 ple and its holder is shown in Fig. 1.

175 The sample dish was automatically raised into the 176 treatment chamber immediately after insertion. The 177 chamber was of dimensions $210 \times 210 \times 226 \mathrm{~mm}$ high 178 and was constructed from an angle iron frame and alu179 minium side panels. The top of the chamber housed a 180 plate of clear safety glass $(160 \times 160 \times 6 \mathrm{~mm}$ thick, Pil181 kington plc, St. Helens, UK) with a $12 \mathrm{~mm}$ diameter 182 hole in the centre for mounting the IR thermometer. 183 Nozzles to deliver hot air, cold air and steam to the sur-
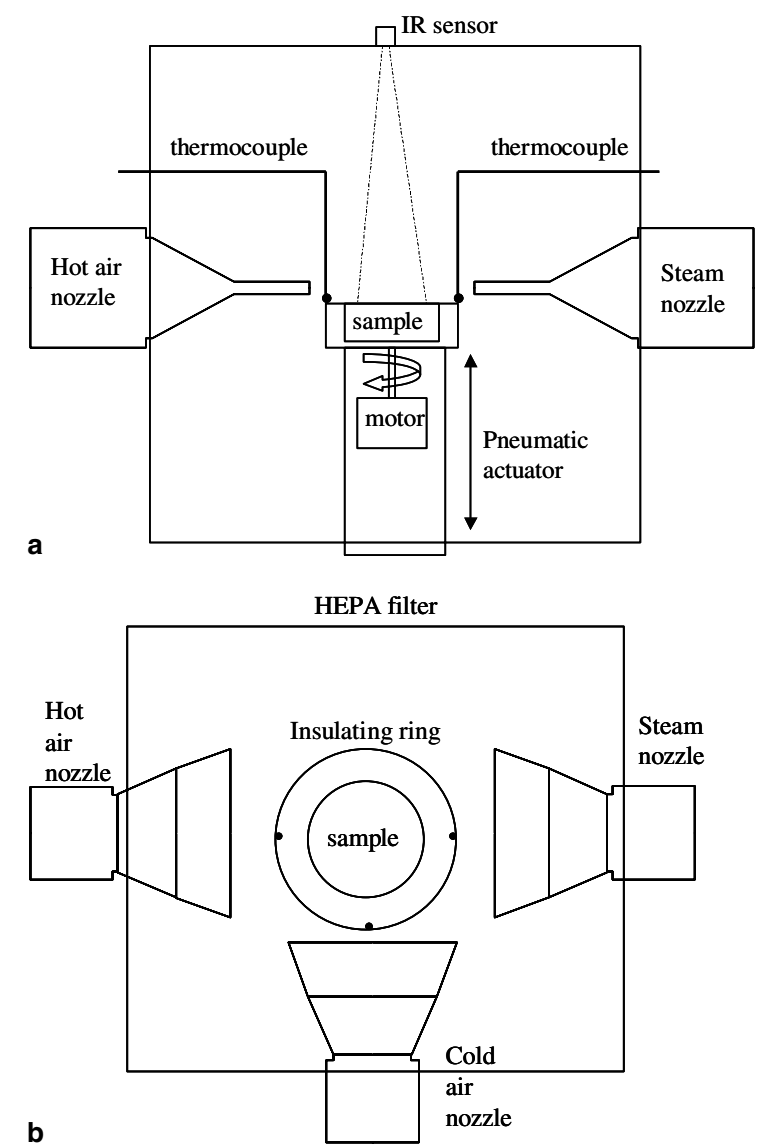

Fig. 1. (a) Vertical section of chamber and (b) plan view of chamber. face of the sample protruded through and were held in place by the side panels.

The main apparatus was designed to be small enough to pass through a standard laboratory doorway and had overall dimensions of $0.7 \times 1.0 \times 2.0 \mathrm{~m}$. A separate refrigeration system, of external dimensions $0.8 \times 0.8 \times 1.2 \mathrm{~m}$, was used to provide cold air for cooling the sample surface. A desktop computer was used to control and monitor system performance. The only services required were: (1) a $230 \mathrm{~V}, 32 \mathrm{~A}$ electrical supply for the main unit, (2) a $230 \mathrm{~V}, 13 \mathrm{~A}$ supply for the refrigeration system and (3) a low flow rate of dry, clean, compressed air at a pressure of 4.0 bar. The air supply could come from either a compressed air line or a compressed air cylinder with regulator.

The glass panel in the top was provided to allow one partner to use a light sensitive camera to view bioluminescent bacteria on the surface of the sample (Lewis, Baldwin, O'Neill, Alloush, \& Nelson, 2005). The apparatus used by this partner was also modified in a number of ways, including the provision of a matt black internal finish to reduce reflections that would interfere with the camera's ability to measure light emissions from the bacteria on the product surface.

Each apparatus was CE marked and provided to the partners with full operating instructions.

\section{Process and control}

Fig. 2 shows a schematic of the chamber and treatment processes. There were three different treatment processes, hot air, cold air and steam.

\subsection{Hot air 'dry' treatment}

Air was taken from ambient and blown through a high-pressure regenerative blower into a $3.3 \mathrm{~kW}$ heater (Robust and Heater 3000, respectively, Leister Process Technologies, Sarnen, Switzerland) via a $25 \mathrm{~mm}$ diameter PVC hose. The hot air from the heater was exhausted through a flat nozzle $(70 \times 4 \mathrm{~mm})$. The nozzle was positioned $30 \mathrm{~mm}$ away from the edge of the sample and $5 \mathrm{~mm}$ above the surface of the sample. The hot air was blown over the sample parallel to its surface and the temperature of the air controlled to give the correct temperature at the product surface at any point in the experiments (explained in more detail in Section 4.6).

\subsection{Steam 'wet' treatment}

A domestic wallpaper stripper (SS76-CE, Earlex Ltd., Surrey, UK), with a $2 \mathrm{~kW}$ element was used to generate steam at atmospheric pressure. The outlet of the steam generator was connected to a three-way L-port $1 / 4$ in. brass ball valve with pneumatic actuation (Everyvalve
84

85
86

\section{7}

\section{8} 90 91 92 93

\section{4}

95

96

97

98

99

00

\section{1} 203

\section{4}

205

06

\section{7} 09

2

3

4

5

7

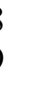

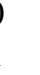

2

4

6

\section{8}




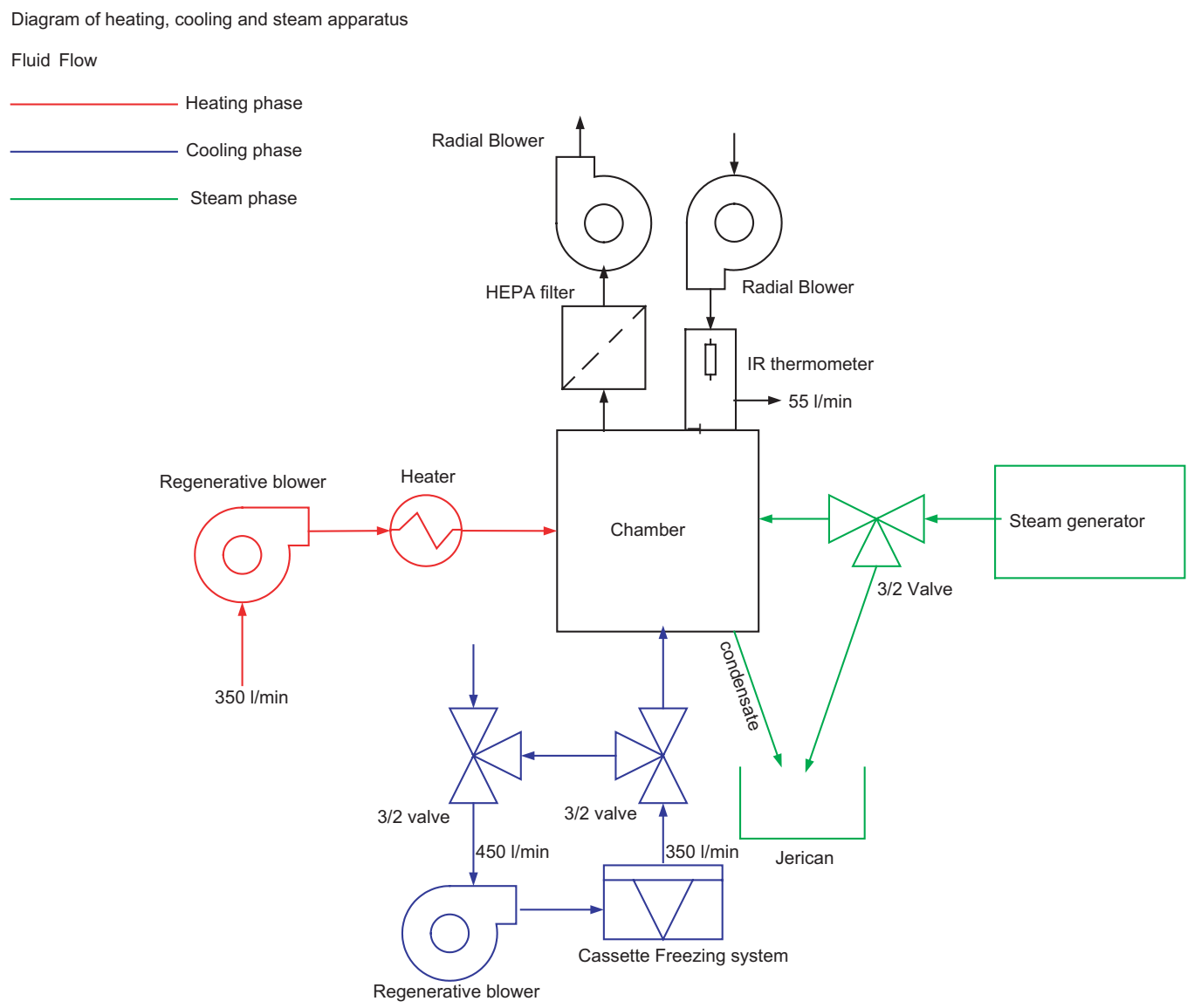

Fig. 2. Schematic of the apparatus showing the treatment equipment.

233 Ltd., Hertfordshire, UK) by a $10 \mathrm{~mm}$ diameter polyure-

234 thane tube. The valve outlets were connected to: (1) a 235 nozzle, positioned $30 \mathrm{~mm}$ from the edge and $5 \mathrm{~mm}$ 236 above the surface of the sample and (2) a PVC tube act237 ing as a vent for the steam when the steaming process 238 was off. The steam exited the nozzle under the slight 239 pressure from the steam generator and was exhausted 240 over the sample parallel to its surface.

241 The chamber and filter were heated using the hot air 242 system (using air at up to $100^{\circ} \mathrm{C}$ for a period of $2 \mathrm{~min}$ ) 243 prior and subsequent to the steam being introduced to 244 avoid condensation in the filter, which could block it 245 and reduce its effectiveness or lead to damage as a result 246 of the high back pressure caused by the blockage. The 247 steam treatment was restricted to $60 \mathrm{~s}$ to keep the build 248 up of moisture in the filter to an insignificant level.

\subsection{Cold air treatment}

Cold air was accumulated by re-circulating it through the evaporator of a refrigeration cassette mounted on top of a chest freezer. The cassette was designed to cool air in an upright freezer $(560 \mathrm{FP}$, Sadia Refrigeration, Sheffield, UK). The chest freezer (AFG 522, Whirlpool 5 UK Ltd., Surrey, UK) was used as an insulated box (refrigeration was not used) to accumulate the cold air for the cooling system. The cassette was positioned above the chest freezer and the top of the chest freezer cut so that air from the chest freezer re-circulated through the evaporator of the cassette, and was cooled. An aluminium frame was used to seal the connection between chest freezer and cassette.

Fig. 2 shows the refrigeration circuit. Two holes were cut in the top of the cassette, one just before the evaporator and one just after, and ports were connected to these holes. A $25 \mathrm{~mm}$ inside diameter PVC hose was attached to each of the two ports; these holes were wrapped with $13 \mathrm{~mm}$ thick rubber pipe insulation (Armaflex, Armstrong Insulation products, Lancs., UK). Cold air from the refrigeration unit was drawn into the treatment chamber using a high-pressure regenerative blower (Robust, Leister Process Technologies, Sarnen, Switzerland). Two three-port air operated valves (VGA342-10A, SMC UK Ltd., Buckinghamshire, UK) allowed air to either recycle through the pipes and blower (this was to allow pre-cooling of the system) or be discharged through a nozzle positioned $15 \mathrm{~mm}$ in front of the sample and $5 \mathrm{~mm}$ above the surface of the sample. 
280 The cooling treatment could only be selected in com281 bination with (and after) a hot air treatment. Cooling 282 was not possible after a wet heat treatment due, to in283 creased condensation problems. The programme pro284 duced a $15 \mathrm{~min}$ pre-cooling phase before the treatment 285 was started, in order to pre-cool as much of the cooling 286 system and pipework as possible, so that the cooling air 287 would be as cold as possible when the cooling phase was 288 initiated.

\subsection{Filtration}

A filtration system was attached to the chamber to 291 contain any bacteria that may have been blown off the 292 samples during the treatments. Air from the chamber 293 was drawn through a high efficiency particulate air 294 (HEPA) filter (SSA/H13/2FL/2Gr, Absolair Filtration 295 Ltd.) of dimensions $210 \times 223 \times 150 \mathrm{~mm}$. This was at296 chamber and would pass through the filter before leaving the chamber.

\subsection{Sample entry}

When the start button on the GUI was pressed, a warning buzzer sounded for a period of $5 \mathrm{~s}$ before a pneumatic actuator (C95KB32-350, SMC Ltd.) raised the sample into the chamber through a hole in the bottom plate of the chamber. When the sample was fully inserted into the chamber, a microswitch was triggered, which sent a signal to the control program to start the treatment.

\subsection{Temperature control}

For 'dry' heating the user entered values for 'temperature at start of heating', 'temperature at end of heating', 'heating duration' and 'holding duration' into the GUI (Fig. 3). The control and logging programme converted this into a heating and holding ramp as shown in Fig. 4. This ramp defined the desired surface temperature history of the sample. The control and logging programme compared the actual surface temperature (measured by an IR thermometer) with the desired surface temperature at $0.5 \mathrm{~s}$ intervals. If the measured temperature was below the desired temperature the heater was switched on, if it was below, the heater was switched off. The

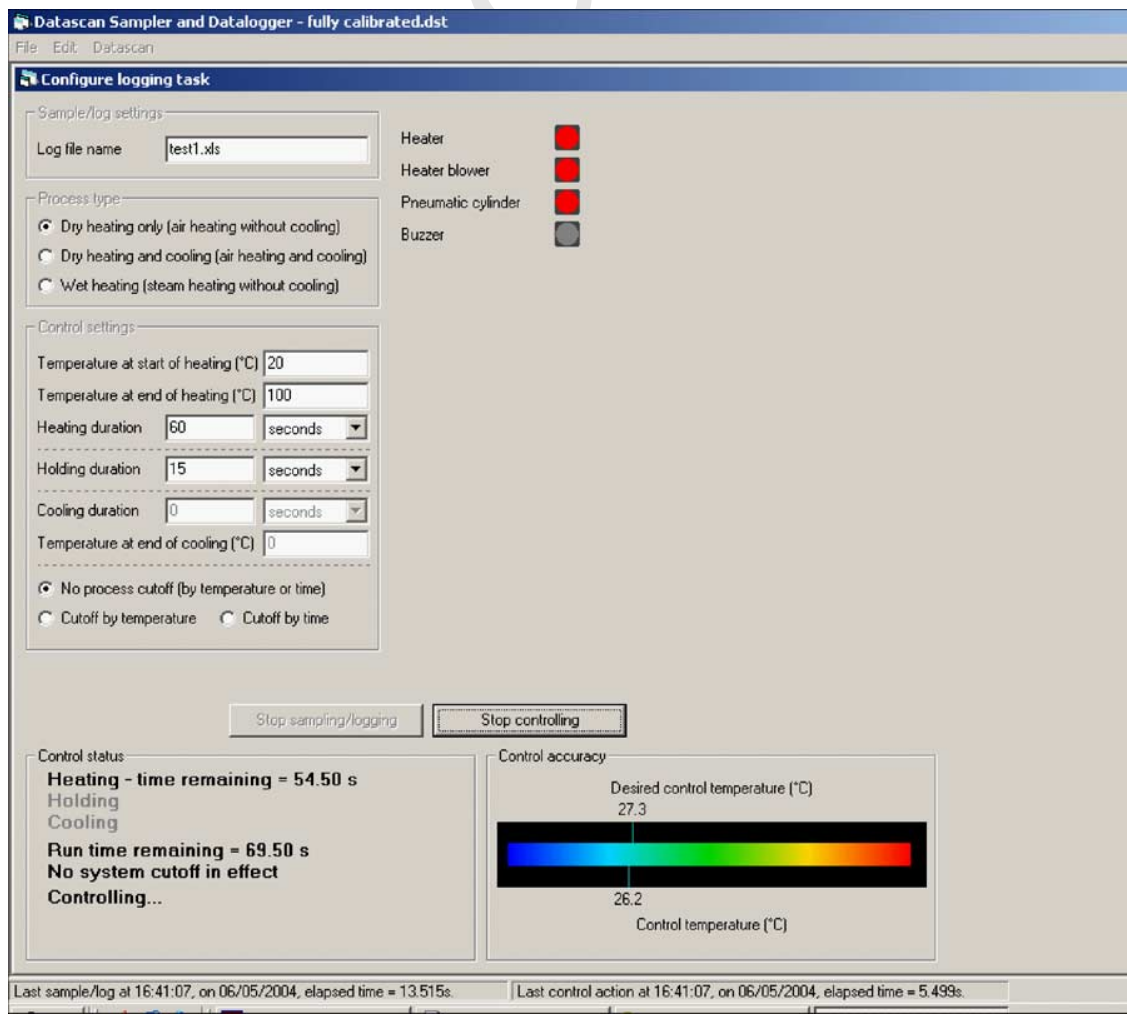

Fig. 3. Screenshot of GUI during a treatment. 


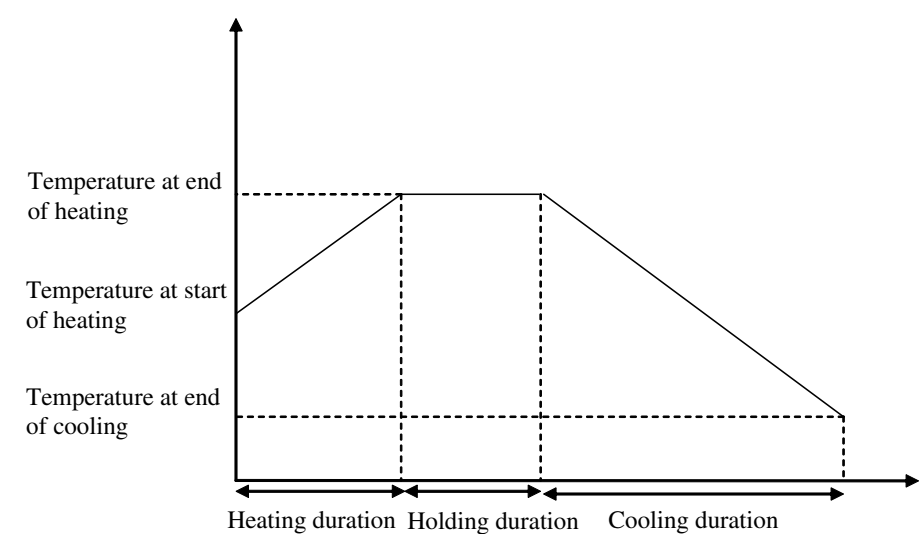

Fig. 4. Desired temperature history given input parameters.

blower remained on during the entirety of the heating and holding periods.

If cooling was specified in the GUI, the user was also required to enter values for 'temperature at end of cooling' and 'cooling duration'. This defined a cooling ramp in the same way as the heating profile. The temperature was controlled at the same interval as the heating process but in the opposite manner (a high temperature turned the cooling on and a low temperature turned it off). If cooling was required, the two pneumatic valves were actuated, allowing cold air to blow into the chamber. If not required, the valves were de-activated, preventing cold air from entering the chamber, but allowing the air to re-circulate around the cooling circuit, keeping as much of it as cold as possible. Unlike during the heating and holding periods, air only passed over the sample when cooling was required.

\subsection{Safety}

An emergency stop button and safety relay were used in the apparatus to allow shutdown and avoidance of all potential hazards. The relay cut power to the heater, blower and released pneumatic pressure to the system removing energy from the actuator. To avoid the apparatus being reset automatically (e.g. after power fluctuations) and potentially becoming hazardous, the emergency stop circuit included a manual start button which had to be pressed after either a cut in power or the emergency stop button being pressed.

A thermal fuse was connected to the wall of the chamber, which would cut the power to the heater if the chamber wall rose above $125^{\circ} \mathrm{C}$. This would be reset automatically when the temperature of the fuse had dropped below $125^{\circ} \mathrm{C}$.

\subsection{Measurement of process conditions}

A 16-channel analogue input measurement processor (Datascan 7320, Measurement Systems Ltd.) measured the temperature of the streams flowing out of the treatment nozzles, the humidity and temperature of the ambient air (outside the rig) and also the temperature of the product surface every $0.5 \mathrm{~s}$ and logged the values in an output file during every treatment. Temperatures of the streams flowing out of the hot air, steam and cold air nozzles were measured at a distance of $1 \mathrm{~mm}$ above the circumference of the insulating ring using Type $\mathrm{K}$ mineral insulated thermocouples with an outside diameter of $3 \mathrm{~mm}$. A combined sensor (Carel ASWC110000, Padova, Italy), situated adjacent to the chamber measured the ambient air temperature and relative humidity.

The prototype rig also had a dew-point temperature transmitter (HMP240, Vaisala Ltd., Suffolk, UK) fitted inside the chamber. This was used to measure the dew point of the air within the chamber during dry and wet treatments.

The surface temperature was measured using a miniature IR thermometer (MID02LT, Raytek UK, Buckinghamshire, UK) with a system accuracy of $\pm 1{ }^{\circ} \mathrm{C}$ and repeatability of $\pm 0.5^{\circ} \mathrm{C}$. The IR thermometer was fixed to the top of the chamber at a height of $90 \mathrm{~mm}$ from the sample surface. Due to its 2:1 optics, the surface temperature was measured over a circle of $45 \mathrm{~mm}$ diameter. The sensor head had to be maintained at a constant temperature to maintain the accuracy of the measurements. A housing was made to fit the sensor, which had inlet and outlet ports that allowed ambient air to be blown through the housing using a radial blower (MVL RG130, Air Control Industries Ltd., Somerset, UK) to stabilise the sensor head temperature. The blower was operated for $30 \mathrm{~min}$ before the treatments to ensure temperature stabilisation stabilise the sensor head temperatures before the start of a treatment.

\subsection{Control and logging}

A 16-channel digital output expansion module (Datascan 7035, Measurement Systems Ltd.) was connected to the measurement processor, enabling it to switch de- 


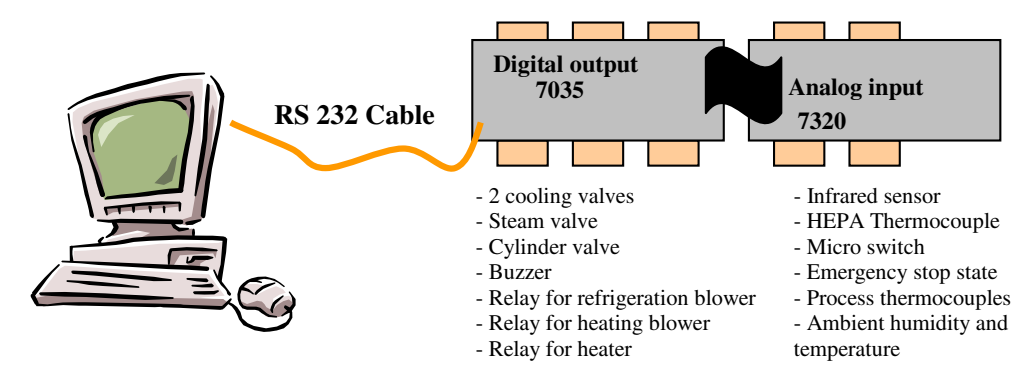

Fig. 5. Connection of control modules.

405 vices connected to each channel on or off, as shown in 406 Fig. 5.

407 The control and logging program was written in 408 Visual Basic 6 (Microsoft) and compiled into an execut409 able file. The executable file was installed on a personal 410 computer (PC) and used to control the processes. The 411 programme controlled all of the process treatments, 412 the movement of the sample, the safety of the system 413 and logged the measured data to disk. The programme 414 received information on the state of the process from 415 the analogue input processor and controlled the process 416 by setting the state of switches on the digital output pro417 cessor. A simplified flow diagram of the control proce418 dure is given in Fig. 6.
The PC (Pentium 4/1.6 GHz, Viglen Ltd.) was connected to the analogue input digital and output processors (situated inside the apparatus) via an RS232 cable. This meant that the PC could be separated from the apparatus, simplifying delivery and positioning of the apparatus.

\subsection{Calibration}

\subsubsection{Calibration of process thermocouples}

The thermocouples used to measure temperatures during the treatments were calibrated in a stirred water bath between 25 and $100{ }^{\circ} \mathrm{C}$ against a platinum
419
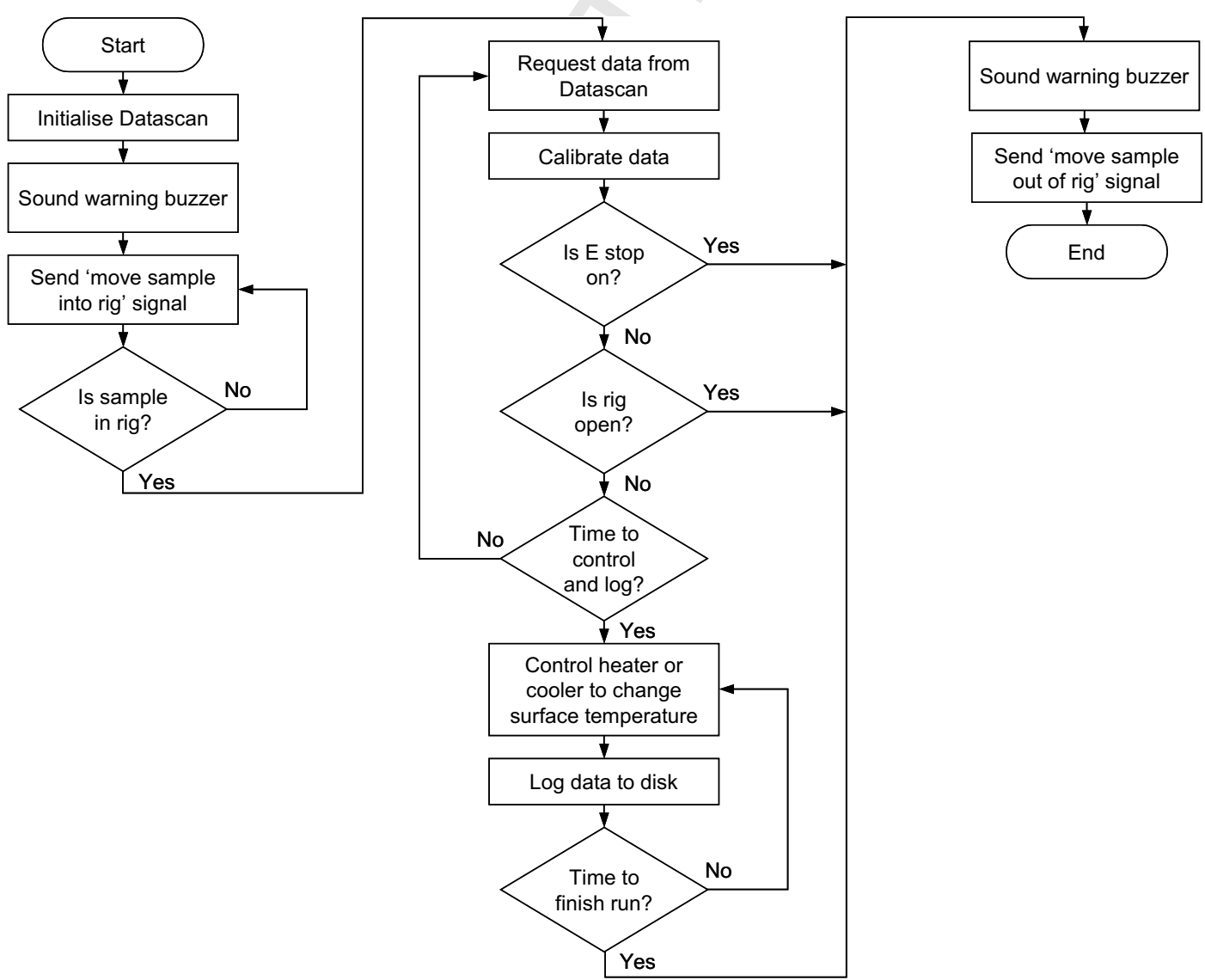

Fig. 6. Simplified flow diagram of control procedure. 
430 resistance thermometer (Fluke 2180A), calibrated to na431 tional standards.

432 4.10.2. Calibration of IR thermometer in a dry

433 environment

434 Experiments were carried out to evaluate an accurate 435 way of calibrating the IR thermometer in a dry environ436 ment. These experiments showed that a uniform temper437 ature could be achieved over the surface of a high 438 conductivity sample if it was placed in the sample holder 439 and heated slowly (from 20 to $100{ }^{\circ} \mathrm{C}$ in $900 \mathrm{~s}$ ). A ther440 mocouple was positioned just below the surface of the 441 high conductivity sample and it was demonstrated that 442 this gave an accurate measurement of surface tempera443 ture at these heating rates. This method of achieving a 444 slowly changing, accurately measured surface tempera445 ture enabled accurate calibration of the IR sensor. The 446 IR thermometer was calibrated in this way using a sam447 ple manufactured from aluminium and its top surface 448 painted matt black. The sample used a type-K thermo449 couple (calibrated as with the process thermocouples, 450 above) placed in the centre, just below the top surface 451 to measure surface temperatures during the heating. 452 Rotation of the sample was unnecessary, as it had been 453 established that the surface would be of uniform temper454 ature during this calibration process. To avoid twisting 455 and breakage of the thermocouple the rotation was 456 therefore stopped by turning off the motor. The IR ther457 mometer was calibrated against the thermocouple in the 458 aluminium sample during the treatment. The emissivity 459 of the matt black surface was assumed to be 1.0 and the 460 settings of the IR thermometer set appropriately.

\section{4.10.3. Calibration of IR thermometer in a wet}

462 environment

463 IR thermometers can accurately measure the product 464 surface temperatures through air. Water in the environ465 ment between the product surface and IR thermometer, 466 both in the form of droplets in the treatment stream and 467 condensed on the surface (as happens during a steam 468 treatment), lead to inaccurate temperature readings.

469 Experiments were carried out to evaluate an accurate 470 way of calibrating the IR thermometer in a wet environ471 ment. There was not a consistent correlation between 472 the surface temperatures measured by the thermocouple 473 in the high conductivity sample and the IR thermome474 475 476 was dependent on initial surface temperature but there 477 was also a highly variable element introduced by forma478 tion of water droplets on the surface (Ulloa, Rouaud, 479 Foster, Kondjoyan, \& Havet, in preparation).

\section{Performance}

\subsection{Surface temperature treatment}

\subsubsection{Dry heating/cooling}

482

The apparatus heated the surface of a sample from 5 to $100{ }^{\circ} \mathrm{C}$ in a duration that was settable by the user. There was also an option to hold the surface temperature at up to $100^{\circ} \mathrm{C}$ for a duration that was settable by the user.

There was no minimum heating duration that could be entered into the GUI. If a duration was entered which was too small for the heating equipment to raise the temperature of the surface to the required temperature in the required time, the heater would heat the product surface at the maximum rate until the end of the heating duration. In these cases, it could be seen from the output file that the 'control temperature' lagged behind the 'desired control temperature'.

Heating tests were carried out in the apparatus using a sample made from a test substance (hydroxyethylmethylcellulose, Gutschmidt, 1960; Riedel, 1960), commonly known as Tylose, a food simulant with similar thermal properties to lean beef. When set to 'maximum heating', the apparatus was able to heat the surface of a Tylose sample from 9 to $100^{\circ} \mathrm{C}$ in $25 \mathrm{~s}$ (Fig. 7), a heating rate of $3.6 \mathrm{~K} \mathrm{~s}^{-1}$. This 'maximum heating' setting heated the sample as quickly as possible to a target temperature, instead of in a straight-line ramp. The temperature of the air exiting the hot air nozzle rose to a maximum of $250{ }^{\circ} \mathrm{C}$ at the end of heating.

When set to 'maximum cooling' (again, cooling as rapidly as possible and so not a straight line ramp), the apparatus was capable of cooling the surface of a Tylose sample from 100 to $40^{\circ} \mathrm{C}$ in $51 \mathrm{~s}\left(1.2 \mathrm{~K} \mathrm{~s}^{-1}\right)$

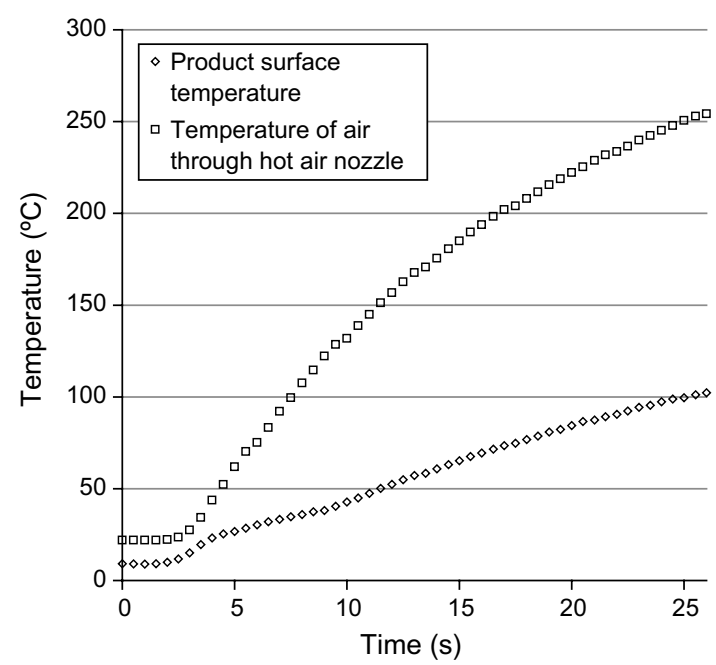

Fig. 7. Temperatures measured on the surface of Tylose and the air exiting the process nozzle for a maximum heating (uncontrolled) treatment.
483

484

485

486

487

488

489

490

491

492

493

494

495

496

497

498

499

500

501

502

503

504

505

506

507

508

509

510

511

512 


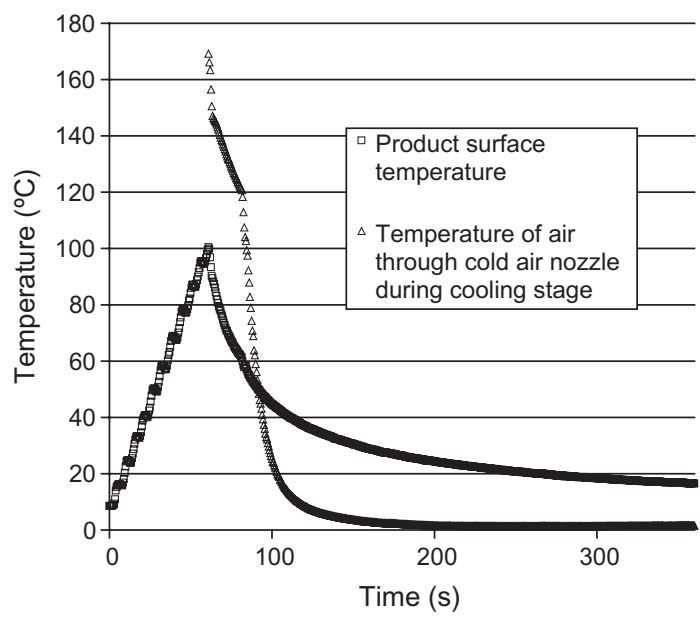

Fig. 8. Temperatures measured on the surface of Tylose and the air exiting the process nozzle for a maximum cooling (uncontrolled) treatment.

513 and to $16.4{ }^{\circ} \mathrm{C}$ in $5 \min \left(0.3 \mathrm{~K} \mathrm{~s}^{-1}\right)$ (Fig. 8). These data 514 were for a sample that had been heated from 5 to $515100{ }^{\circ} \mathrm{C}$ in $60 \mathrm{~s}$ (in a controlled, straight line ramp, with516 out holding at $\left.100{ }^{\circ} \mathrm{C}\right)$.

517 The rate of cooling was significantly lower than the 518 rate of heating. The reason for the slow cooling is shown 519 by the temperature history of the air exiting the cold 520 nozzle. The cold air was $170{ }^{\circ} \mathrm{C}$ at the start of cooling 521 and took a further $31 \mathrm{~s}$ to fall below the surface temper522 ature of the sample $\left(51^{\circ} \mathrm{C}\right)$. The main reason for this 523 was that the temperature of the cooling nozzle rose sig524 nificantly during the heating treatment as it was heated 525 by the hot air from the heating nozzle. This in turn 526 heated the cold air as it was blown into the chamber. 527 The air from the cold air nozzle reached a minimum 528 of $1{ }^{\circ} \mathrm{C}$ during the cooling treatment.

529 Fig. 9 shows the temperature history of a sample of 530 Tylose, with a heating treatment of $5-60^{\circ} \mathrm{C}$ in $30 \mathrm{~s}$, fol531 lowed by holding at $60{ }^{\circ} \mathrm{C}$ for $30 \mathrm{~s}$ and then a cooling

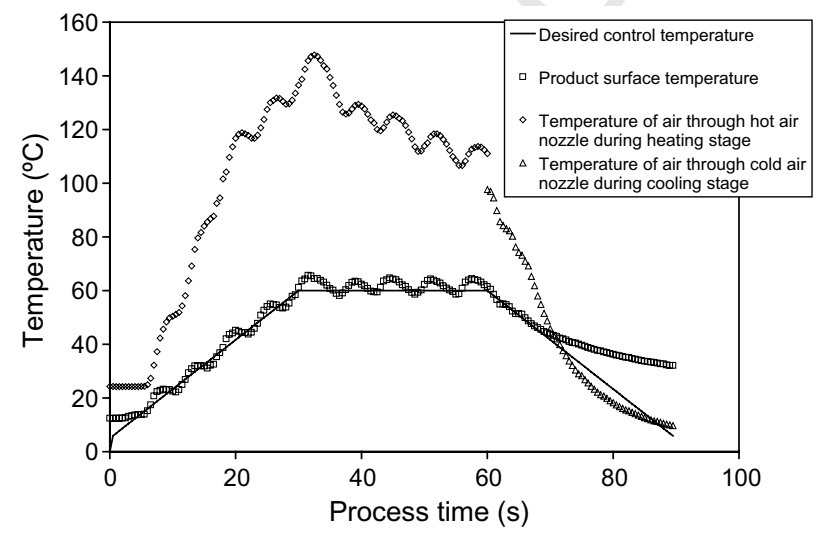

Fig. 9. Temperature history for a Tylose sample with a $5-60{ }^{\circ} \mathrm{C}$ in $30 \mathrm{~s}$ heating treatment followed by a $30 \mathrm{~s}$ holding period and a $60-5^{\circ} \mathrm{C}$ in 30 s cooling treatment. treatment of $60-5^{\circ} \mathrm{C}$ in $30 \mathrm{~s}$. The temperatures of the 532 air at the exit of both the heating and cooling nozzles are also shown during their respective treatments. The temperature of the sample can be seen to fluctuate above and below the desired control temperature as the heater switches on and off. The average absolute errors were $1.7^{\circ} \mathrm{C}$ during the heating ramp and $2.4{ }^{\circ} \mathrm{C}$ during the holding period. The surface temperature was, on average, higher than the desired control temperature because the rate of heating was much higher than the rate of cooling, meaning that one $0.5 \mathrm{~s}$ control increment of heating increased the temperature more than one increment of cooling reduced it. For the first $5 \mathrm{~s}$ after holding, the cooling valves cycled on and off to keep the surface at the desired temperature. After this point the actual cooling rate was less than the desired rate and so the cooling was always on.

\subsection{Steam}

549

It is not possible to show the temperature history of 550 the surface during a wet heat experiment, as the IR thermometer did not provide a meaningful surface temperature. This is explained in Section 4.10.3.

\subsection{Humidity measurements}

During hot air treatments on moist products, the dew point temperature inside the chamber did not change by more than $2{ }^{\circ} \mathrm{C}$ (the accuracy of the dew point sensor at those conditions). This showed that the moisture evaporated from the sample surface was expelled from the chamber.

Fig. 10 shows the temperature history during a wet heat treatment. The dew point temperature quickly rose to a temperature just below the dry bulb temperature at

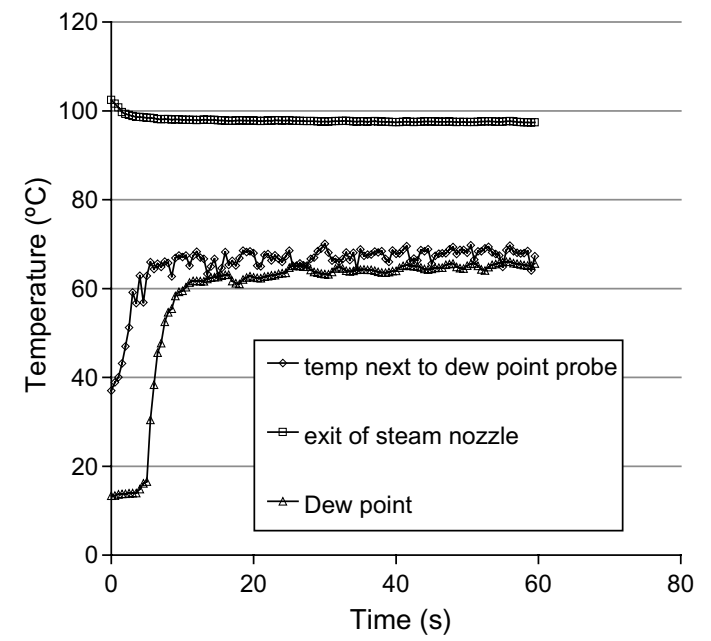

Fig. 10. Temperature history during a wet heat treatment on a Tylose sample. 
564 the position of the dew point probe, giving a relative 565 humidity $(\mathrm{RH})$ of nearly $100 \%$. As the product sample 566 was closer to the wet heating stream than the dew point 567 sensor, it was assumed that the RH over the sample was $568100 \%$

\section{9}

\subsection{Uniformity of heating}

Two methods were used to measure the uniformity of heating. The first was using thermocouples just under was using an IR thermal imaging camera.

\subsection{Thermocouple method}

The aluminium sample used in these experiments was similar to that used in Section 4.10, except that it had a second thermocouple placed $16 \mathrm{~mm}$ from the centre, just under the surface. This thermocouple was used to measure either leading or trailing edge temperatures, depending on the orientation of the sample to the hot air nozzle. To avoid breakage of the thermocouples during these experiments the sample rotation was disabled as in Section 4.10.

The advantage of this method was that a history of the temperature uniformity was measured during the entire heating process. However, this method was not very comparable to the process that the food samples underwent, as the aluminium sample would have had very different thermophysical properties to the foods that were processed in the apparatus and the rotation of the sample was disabled, which would have caused larger temperature differences on the surface than if it had been rotating.

\subsection{Thermal imaging method}

A thermal imaging camera (ThermaCam E4, FLIR Systems AB, Sweden) was used to determine the temperatures on the surface of a Teflon sample, after a rapid, high temperature dry heating treatment $\left(20-100^{\circ} \mathrm{C}\right.$ in $60 \mathrm{~s}$ ). The camera had been calibrated using radiation sources that are traceable to National Standards. The emissivity of the camera was set to 0.95 . It was not possible to take the image to measure temperatures whilst the sample was in the chamber and therefore the sample was removed from the apparatus directly after heating and the thermal image taken as soon as possible. The duration between end of heating and taking the image was $9 \mathrm{~s}$. The same heating treatment was applied to Tylose samples with and without sample rotation.

The advantage of this method was that real surface temperatures were measured at all positions on the sur1 face of a sample that had similar properties on a food product. The only disadvantage was that it was not pos- sible to measure temperature data using the camera during the heating process or immediately afterwards.

\subsection{Dry air treatment}

Fig. 11 shows the temperature history during a rapid hot air treatment followed by a holding period using the thermocouple method. The heater was unable to maintain the specified heating gradient and therefore gave maximum heating until the holding period. The difference between the leading and trailing edge temperatures reached a maximum of $10^{\circ} \mathrm{C}, 25 \mathrm{~s}$ after the treatment started.

Fig. 12 shows the thermal image $9 \mathrm{~s}$ after a rapid hot air treatment with no sample rotation. It can be seen that there is a temperature gradient from top to bottom, representing the leading and trailing edge of the sample. The maximum and minimum surface temperatures of

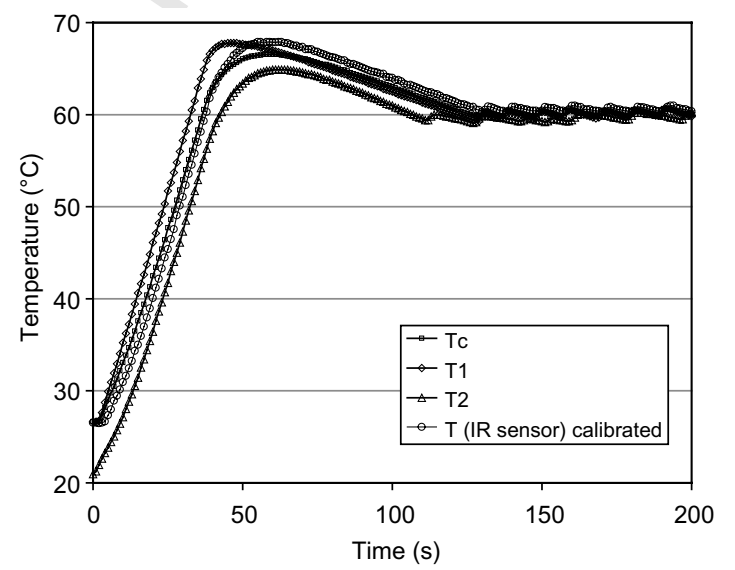

Fig. 11. Temperature history during a fast hot air treatment. Centre thermocouple (Tc), leading edge thermocouple (T1), IR sensor temperature (T(IR sensor)) and trailing edge thermocouple (T2) are plotted.

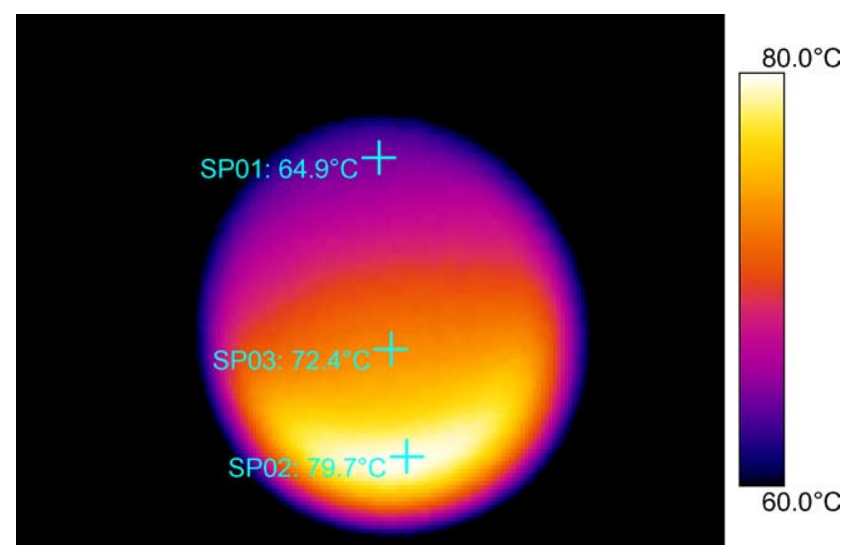

Fig. 12. Temperature uniformity taken by a thermal imaging camera, $9 \mathrm{~s}$ after heating to $100{ }^{\circ} \mathrm{C}$ in $60 \mathrm{~s}$. Sample rotation was disabled. 


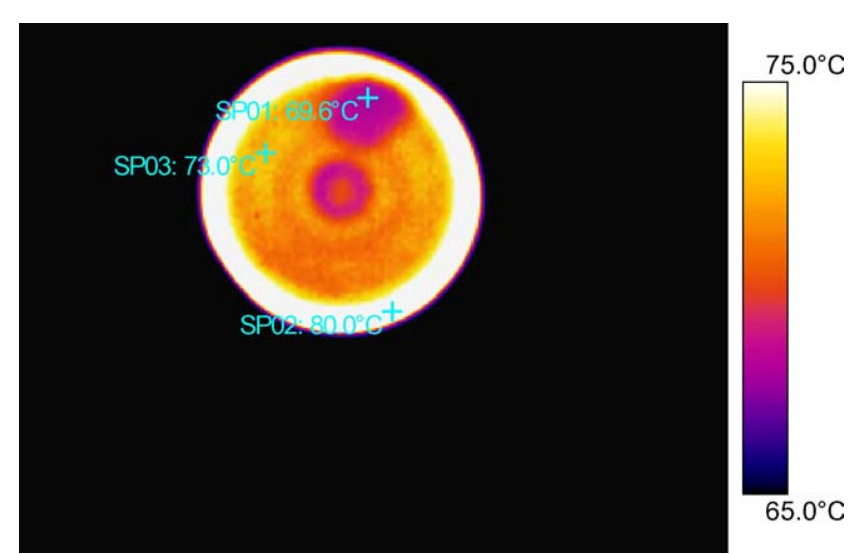

Fig. 13. Temperature uniformity taken by a thermal imaging camera, $9 \mathrm{~s}$ after heating to $100{ }^{\circ} \mathrm{C}$ in $60 \mathrm{~s}$.

629 the bulk of the sample were 79.7 and $64.9{ }^{\circ} \mathrm{C}$ 630 respectively.

631 Fig. 13 shows the thermal image $9 \mathrm{~s}$ after a rapid hot 632 air treatment with sample rotation. A hot ring $\left(80^{\circ} \mathrm{C}\right)$ 633 can be seen around the edge of the sample, representing 634 the glass and perhaps the outer edge of the sample. The 635 maximum and minimum temperatures of the bulk of the 636 sample (inside the hot ring) were 73.0 and $69.6{ }^{\circ} \mathrm{C}$ 637 respectively.

638 The reduced average temperature of the sample 639 (approximately $70^{\circ} \mathrm{C}$ ) represents the rapid cooling of 640 the surface that occurs by conduction from the bulk of 641 the sample to the surface and heat exchange with the 642 environment during the $9 \mathrm{~s}$ between the end of heating 643 and taking the thermal image.

\section{5.7.1. Wet treatment}

645 Fig. 14 shows the temperature history during a $60 \mathrm{~s}$ 646 steam treatment using the thermocouple method. The 647 temperature exiting the steam nozzle reached $100{ }^{\circ} \mathrm{C}$ 648 after $2 \mathrm{~s}$. There was a difference between leading and

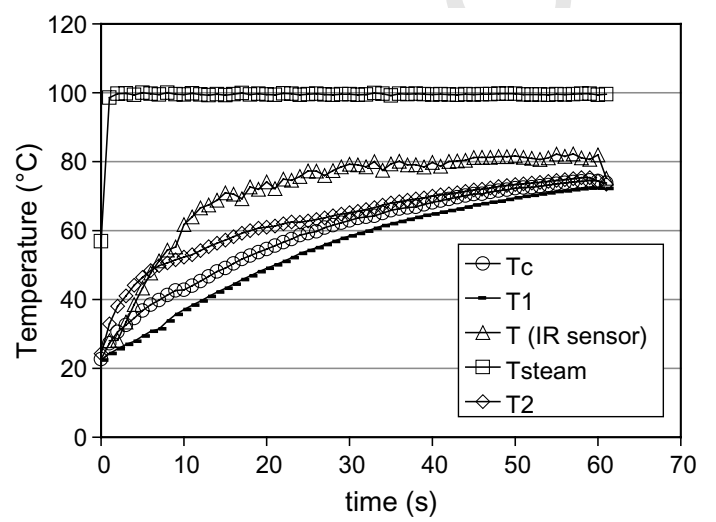

Fig. 14. Temperature history during a $60 \mathrm{~s}$ steam treatment. Steam temperature (Tsteam) centre thermocouple (Tc), trailing edge thermocouple (T1), IR sensor temperature (T(IR sensor)) and leading edge thermocouple (T2) are plotted. trailing edge temperatures that reached a maximum of $18{ }^{\circ} \mathrm{C}, 7 \mathrm{~s}$ after the treatment started.

\section{Discussion and conclusion}

Test apparatus to heat a sample from a given surface temperature at a given rate, hold the sample at a given temperature for a defined period and cool the sample in a controlled manner has been built and its performance evaluated. Four more versions of these apparatus were built, CE marked, shipped to project partners and used to obtain bacterial death data.

The apparatus can either heat in a dry (hot air) or wet (steam) manner. The apparatus included a HEPA filtration system to contain bacteria and the ability to view the sample from above during treatments with a light sensitive camera. The apparatus has proved to be simple to use, safe and reliable.

Surface temperatures were controlled using temperatures measured by a calibrated IR thermometer during the dry experiments. It was not possible to obtain reliable measurements from the IR thermometer during wet heating treatments and so these treatments were controlled on duration only.

The apparatus was shown to heat a Tylose (meat simulant) sample from 9 to $100^{\circ} \mathrm{C}$ at a rate of up to $3.6 \mathrm{~K} \mathrm{~s}^{-1}$ and cool it to $40^{\circ} \mathrm{C}$ at a rate of up to $1.2 \mathrm{~K} \mathrm{~s}^{-1}$ then to $16.6^{\circ} \mathrm{C}$ at a rate of up to $0.3 \mathrm{~K} \mathrm{~s}^{-1}$. Temperature control to a defined ramp was achieved at an average accuracy of $1.7^{\circ} \mathrm{C}$ and $2.4^{\circ} \mathrm{C}$ on the sample surface, during heating and holding periods, respectively.

It was not possible to measure temperature uniformity during a real treatment on real food. A maximum surface temperature difference of $10^{\circ} \mathrm{C}$ and $18{ }^{\circ} \mathrm{C}$ were recorded (with thermocouples) for air and steam respectively, just under the surface of an aluminium sample without sample rotation. Thermal imaging allowed temperatures across the surface of a Tylose sample to be measured $9 \mathrm{~s}$ after a rapid heating treatment. These showed a large temperature difference of $14.8{ }^{\circ} \mathrm{C}$ between the leading and trailing edge without sample rotation, but a much smaller temperature difference of $3.4{ }^{\circ} \mathrm{C}$ with sample rotation.

Delivering the treatment streams across (parallel to) the surface of the sample allowed the space above the sample to be used for surface temperature measurement using an IR thermometer and viewing with a light sensitive camera. However, delivering the treatment streams across the surface was not ideal, as it led to uneven surface temperatures. Temperature uniformity was greatly increased by sample rotation although this did not allow measurement of sample temperatures with thermocouples.

\section{2}

653

654

655

656

657

658

659

660

661

662

663

664

665

666

667

668

669

670

671

672

673

674

675

676

677

678

679

680

681

682

683

684

685

686

687

688

689

690

691

692

693

694

695

696

697 
Carrying out both the cooling and heating in the same chamber caused the cooling to be less effective than originally intended. The slow rate of cooling was due to delivery of cold air into the chamber through a nozzle that had been previously heated by the air exiting the heating nozzle during the heating/holding treatment. The air also absorbed heat as it passed through the blower.

An improved apparatus which addresses many of these issues has been built and tested and is described in another publication in this Journal Special Edition (Foster et al., 2005).

\section{Uncited references}

\section{Acknowledgements}

716 This work was funded as part of the European Union 717 Framework Five project 'Bugdeath' QLRT-2001-01415.

718 We acknowledge and are grateful for the close collabo719 ration of all the partners in this project. Finally, we 720 thank the foreign exchange students, who visited FRP721 ERC and worked on the design and building of the 722 apparatus, especially Emiliano Bartolini whose input 723 was invaluable.

\section{References}

Foster, A. M., Ketteringham, L. K., Purnell, G. L., Kondjoyan, A., Havet, M., \& Evans, J. A. (2005). Design and development of improved apparatus to provide repeatable surface temperaturetime treatments on inoculated food samples. Journal of Food Engineering (this issue).

Gutschmidt, J. (1960). Über das herstellen und verpacken der karlsuher prüfmasse (On manufacture and packing of the Karlsruhe test substance). Kältetechnik, 12 Jahrgang, Vol. 8, pp. 226229.

Hoke, K., Housska, M., Kyyhos, K., Landfeld, A., \& Pipekb, P. (2003). Modelling of beef surface temperatures during steam decontamination. Journal of Food Engineering, 58, 95-102.

James, C., Goksoy, E. O., Corry, J. E. L., \& James, S. J. (2000). Surface pasteurisation of poultry meat using steam at atmospheric pressure. Journal of Food Engineering, 45, 153-160.

James, S. J., \& Evans, J. A. (2005). Predicting the reduction in microbes on the surface of foods during surface pasteurisationthe 'BUGDEATH' project. Journal of Food Engineering (this issue)

Lewis, R. J., Baldwin, A., O'Neill, T., Alloush, H., Nelson, S. M., et al. (2005). Use of Salmonella enterica serovar Typhimurium DT104 expressing lux genes to assess, in real time and in situ, heat inactivation and recovery on a range of contaminated food surfaces. Journal of Food Engineering (this issue).

McGovern, A. C., McCann, M. S., \& Sheridan, J. J. (2005). Microbiological protocol for project: 'Predicting microbial death during heat treatments on foods'. Journal of Food Engineering (this issue).

Riedel, L. (1960). Eine prüfsubstanz für gefrierversuche (A test substance for freezing experiments). Kältetechnik, 12 Jahrgang, Vol. 8, pp. 222-225.

Soto, V., \& Borquez, R. (2001). Impingement freezing of biomaterials. Food Control, 12, 515-522.

Ulloa, R. Z., Rouaud, O., Foster, A. M., Kondjoyan, A. M., \& Havet, M. (in preparation). Applied Thermal Engineering. 